\title{
Design and evaluation of rectal drug delivery systems of non-steroidal anti-inflammatory drug
}

\author{
PV Swamy ${ }^{1}$, *Mohammed Younus Ali², Y Anand Kumar ${ }^{3}$, K Prasad ${ }^{1}$, N Srinivaslu ${ }^{3}$ \\ ${ }^{1}$ Sr. Professor, Department of Pharmaceutical Technology, Shri Vishnu College of Pharmacy, Vishnupur, Bhimavaram-534 202, \\ West Godavari, Andhra Pradesh, India \\ ${ }^{2}$ KCT College of Pharmacy, Gulbarga, India \\ ${ }^{3}$ V.L College of Pharmacy, Raichur, India
}

\begin{abstract}
The aim of the present study was to design and evaluate the suppositories of aceclofenac a non-steroidal anti inflammatory drug (NSAID). Aceclofenac, rectal suppositories were developed by employing various hydrophilic and hydrophobic polymeric bases like gelatin, PEG-400 and hydrogenated vegetable oil using propylene glycol as plasticizer and beeswax as hardening agent. The in-vitro release rate data was evaluated statistically and was found that from all the formulations the drug release is by diffusion mechanism ( $r=0.9547$ to 0.9967$)$ according to Higuchi's equation. All the prepared formulations have shown zero-order release kinetics except those prepared by utilizing $15 \%$ and $20 \%$ of PEG-400. The formulation prepared using $7.5 \%$ beeswax in hydrogenated vegetable oil has displayed zero-order drug release $(r=0.9927)$ and has released $99.18 \%$ of the aceclofenac within $4 \mathrm{~h}$, hence, this formulation is considered as a promising formulation. The stability study on the promising formulation was conducted over a period of 6 months and found that there are no significant changes in the drug content and in-vitro drug release rate $(\mathrm{p}<0.05)$. The result suggests that the suppositories can be prepared by employing hydrophilic and hydrophobic polymers.
\end{abstract}

Key Words: Suppositories, diffusion, hydrogenated vegetable oil, beeswax, zero order, stability studies.

\section{INTRODUCTION}

Suppositories are medicated solid bodies suitably shaped for rectal administration (British Pharmaceutical Codex, 1968). To avoid various unwanted effects associated with oral therapy, the focus was on rectal drug delivery. For a long period of time, the rectal route was used only for the administration of local anesthetics, anti-haemorrhoidal, vermifugal and laxative agents. Now the majority of the drugs are formulated in the form of suppositories to produce systemic effect. The elimination of the drugs subjected to the first-pass effect in the liver and/or pre-systemic metabolism in the gastrointestinal tract may be partially avoided by rectal administration (Herman, 1995). Rectal route of

\footnotetext{
*Corresponding Author:

Mohammed Younus Ali

Principal, KCT College of Pharmacy

P. Box No.-104, Qamar Ul Islam Colony

Gulbarga-585104, Karnataka, India

E-mail:yns123@rediffmail.com
}

administration is specifically useful for infants and children who have difficulty in swallowing oral medicine. Blood draining the lower part of the rectum largely by-passes the liver so that drugs showing a high first-pass metabolism when given orally are more effectively absorbed when administered rectally (Rytting and Fix, 2002). Further advantages include: (a) improved enzymatic drug stability, (b) higher drug load, (c) constant and static environment, (d) improved patient compliance, particularly for children and elderly people with swallowing difficulty, (e) avoidance of overdosing (Rawlins, 2002). Drugs are introduced into the rectum either as solid (suppositories) or as liquid (enemas) for local and systemic action (Rawlins, 2002). The suppository may be useful for long-term treatment of chronic diseases like essential hypertension, rheumatoid arthritis, asthma, diabetes, AIDS, anemia, etc. Many researchers have concentrated their efforts in rectal drug absorption on those drugs, which currently must be injected parenteral- 
Table 1: Composition of suppository formulations.

\begin{tabular}{|c|c|c|c|c|c|c|c|c|c|c|}
\hline S1. No. & Ingredients & $\mathrm{AVS}_{1}$ & $\mathrm{AVS}_{2}$ & $\mathrm{AVS}_{3}$ & $\mathrm{AVS}_{4}$ & $\mathrm{AVS}_{5}$ & APGS $_{1}$ & APGS $_{2}$ & $\mathrm{APGS}_{3}$ & APGS \\
\hline 1. & $\begin{array}{l}\text { Hydrogenated } \\
\text { vegetable oil }(\mathrm{g})\end{array}$ & 23.58 & 23.91 & 24.24 & 24.6 & 8.30 & - & - & - & - \\
\hline 2. & Beeswax (g) & 2.61 & 2.28 & 1.962 & 1.62 & 1.32 & - & - & - & - \\
\hline 3. & Gelatin (g) & - & - & - & - & - & 6.00 & 6.00 & 6.00 & 6.00 \\
\hline 4. & PEG $400(\mathrm{~g})$ & - & - & - & - & - & - & 3.00 & 4.5 & 6.00 \\
\hline 5. & Propylene glycol (g) & - & - & - & - & - & 15.00 & 12.00 & 10.5 & 9.00 \\
\hline 6. & Propyl paraben (g) & - & - & - & - & - & 0.3 & 0.3 & 0.3 & 0.3 \\
\hline 7. & Distilled Water (ml) & - & - & - & - & - & 3.0 & 3.0 & 3.0 & 3.0 \\
\hline 8. & Drug (mg) & 6.00 & 6.00 & 6.00 & 6.00 & 6.00 & 6.00 & 6.00 & 6.00 & 6.00 \\
\hline
\end{tabular}

ly, to provide effective therapy (e.g., antibiotics and polypeptides).

Aceclofenac (Sweetman, 2005) is a new generation NSAID widely used in the long term therapy of various rheumatic disorders and is associated with gastro-intestinal effects such as gastric irritation and ulceration which can be prevented by administering through rectum in the form of solid suppositories. In the present study, rectal suppositories of ACL were developed by using different hydrophilic and hydrophobic polymeric bases like gelatin, PEG-400 and hydrogenated vegetable oil using propylene glycol as plasticizer and beeswax as hardening agent. Fat like bases are used for water-soluble drugs and a hydrophilic base for a drug, insoluble in water (Herman, 1995).

\section{MATERIALS AND METHODS}

ACL was a generous gift from M/s. Glenmark Pharmaceuticals, Nasik, Maharastra, India. Propylene glycol, polyethylene glycol 400 (PEG 400) were procured from Sd Fine Chem Ltd., Mumbai. Gelatin and propylparaben were purchased from Qualigens Fine Chemicals, Loba Chemie Pvt Ltd and Merck Specialities Pvt Ltd, Mumbai, respectively. All other chemicals used were of analytical reagent grade.

\section{Calibration of Mould and displacement value}

Before preparing the suppositories, the mould should be calibrated because the moulds may vary in their capacity. The base was melted alone and then filled into the mould and weighed after removing the suppositories; the mean weight was taken as true capacity of the mould. The procedure was repeated for different bases. The calibrated mould capacities ranged from 1.02 to $1.195 \mathrm{~g}$ for hydrogenated vegetable oil suppositories and 1.224 to $1.329 \mathrm{~g}$ for gelatin base suppositories (Carter, 2008).

\section{Preparation of suppositories}

Hydrogenated vegetable oil suppositories were prepared using fusion (pour-molding) method (Coben and Liberman, 1989). Hydrogenated vegetable oil was taken in a china dish and melted. The drug was dispersed in the melted oil; after complete dispersion, the melted base along with drug was poured into the pre-calibrated mould (rapid cooling should be avoided as it results in holing of the suppositories).

For the preparation of gelatin suppositories, gelatin was added to water and heated. In the mixture of propylene glycol and PEG 400, accurately weighed amounts of drug and preservative (propylparaben) were added. This solution was then added to the solution of gelatin and heated on water bath at 70$80^{\circ} \mathrm{C}$, stirred to yield homogeneous solution and the solution transferred into the pre-calibrated mould and cooled immediately which is very essential for gelatin suppositories. The drug loaded in each suppository was $200 \mathrm{mg}$. The prepared suppositories were wrapped in aluminum foil and stored under refrigeration. Batches of 30 suppositories were prepared for all the designed formulations. The composition of all batches of suppositories is shown in Table 1.

\section{Evaluation of suppositories}

The prepared suppositories were evaluated for physical appearance by visual examination, weight uniformity, drug content uniformity, liquefaction 
Table 2: Evaluation of suppositories.

\begin{tabular}{|c|c|c|c|c|c|}
\hline \multirow{2}{*}{$\begin{array}{l}\text { Formulation } \\
\text { code }\end{array}$} & \multirow{2}{*}{$\begin{array}{l}\text { Weight variation* } \\
\text { (mean } \pm \text { SD) }\end{array}$} & \multirow{2}{*}{$\begin{array}{l}\text { Drug content } \\
\text { (mean } \pm \text { SD) }\end{array}$} & \multicolumn{2}{|c|}{ Liquefaction time/temperature } & \multirow{2}{*}{$\begin{array}{l}\text { Micro melting } \\
\text { range }\left({ }^{\circ} \mathrm{C}\right)\end{array}$} \\
\hline & & & Time (min) & Temp $\left({ }^{\circ} \mathrm{C}\right)$ & \\
\hline$\overline{\mathrm{AVS}_{1}}$ & $1.152 \pm 0.019$ & $98.20 \pm 0.0062$ & 6.0 & 37 & $36-39$ \\
\hline $\mathrm{AVS}_{2}$ & $1.152 \pm 0.019$ & $95.58 \pm 0.002$ & 5.0 & 37 & $37-38$ \\
\hline $\mathrm{AVS}_{3}$ & $1.150 \pm 0.018$ & $96.04 \pm 0.0015$ & 3.0 & 37 & $36-38$ \\
\hline $\mathrm{AVS}_{4}$ & $1.10 \pm 0.0114$ & $98.50 \pm 0.0012$ & 5.0 & 37 & $37-38$ \\
\hline $\mathrm{AVS}_{5}$ & $1.09 \pm 0.010$ & $98.00 \pm 0.006$ & 3.0 & 37 & $36-38$ \\
\hline $\mathrm{APGS}_{1}$ & $1.32 \pm 0.0021$ & $98.20 \pm 0.001$ & 3.5 & 37 & $36-37$ \\
\hline $\mathrm{APGS}_{2}$ & $1.22 \pm 0.946$ & $97.90 \pm 0.001$ & 3.0 & 37 & $36-38$ \\
\hline $\mathrm{APGS}_{3}$ & $1.23 \pm 0.531$ & $98.60 \pm 0.0046$ & 3.0 & 37 & $37-38$ \\
\hline $\mathrm{APGS}_{4}$ & $1.22 \pm 0.091$ & $98.77 \pm 0.0057$ & 4.0 & 37 & $36-38$ \\
\hline
\end{tabular}

${ }^{*}$ Average of three determinations

time and temperature, micro-melting range and short term stability. The physical examination was carried as per USP-30/NF-25 and was found that there was no fissuring, pitting and fat blooming. For determining the weight uniformity, twenty suppositories were weighed individually and the average weight was determined. The individual weights were compared with the average weight for determination of weight variation and were found that no suppository deviates from average weight by more than $5 \%$, and thus prepared suppositories comply with IP specifications (Indian Pharmacopoeia, 1996). The determination of drug content was carried out by slicing 10 suppositories into small pieces, suppository pieces equivalent to $100 \mathrm{mg}$ ACL were accurately weighed and transferred into $100 \mathrm{ml}$ volumetric flask and dissolved in $50 \mathrm{ml}$ methanol by shaking for $90 \mathrm{~min}$ on a gyratory shaker (KEMI, Cochin, India) at $150 \mathrm{rpm}$, and the volume was made up to the mark with methanol. The absorbance of the solution was measured at 276nm against the solvent blank (Pharmaspec-1700, Shimadzu, Japan). The drug content was calculated

Table 3: In-vitro drug release data.

\begin{tabular}{llccl}
\hline $\begin{array}{l}\text { Sl. } \\
\text { No }\end{array}$ & Cormulation & $\begin{array}{c}\mathbf{t}_{50} \% \\
(\mathbf{m i n})\end{array}$ & $\begin{array}{c}\mathbf{t}_{70 \%} \\
(\mathbf{m i n})\end{array}$ & $\begin{array}{l}\text { Cumulative } \% \\
\text { drug release }\end{array}$ \\
\hline 01 & AVS1 & 120.0 & 166.0 & $98.97 \pm 0.5773$ \\
02 & AVS2 & 81.0 & 120.0 & $98.00 \pm 1.8110$ \\
03 & AVS3 & 82.0 & 146.0 & $99.18 \pm 0.2527$ \\
04 & AVS4 & 72.0 & 136.5 & $99.20 \pm 0.5778$ \\
05 & AVS5 & 80.0 & 116.0 & $98.37 \pm 0.7919$ \\
06 & APGS1 & 52.5 & 90.0 & $96.02 \pm 1.1873$ \\
07 & APGS2 & 37.5 & 76.5 & $97.20 \pm 0.9873$ \\
08 & APGS3 & 27.5 & 52.0 & $99.75 \pm 0.1843$ \\
09 & APGS4 & 24.0 & 49.5 & $98.10 \pm 0.2583$ \\
\hline
\end{tabular}

from the calibration curve. Average of five determinations was taken as mean drug content of the suppositories (Table 2). For determination of liquefaction time and temperature (Baswaraj and Nanjundswamy, 2005), a simple apparatus with modification, fabricated in the laboratory, has been used. A centrifuge tube with broken bottom was taken and cut suitably so that it is having a narrow opening at the bottom. The centrifuge tube was kept in hot water maintained at $37^{\circ} \mathrm{C}$, so that narrow end faces towards hot water. The suppository was introduced from the top of the tube through broad end and carefully pushed down its length until it reaches the narrow end. A glass rod weighing $30 \mathrm{~g}$ was then inserted so that it rests over the suppository. The temperature at which the glass rod just comes down was noted which represents the liquefaction temperature. The time at which glass rod reaches to narrow end after complete melting of suppository represents the liquefaction time. For micro- melting range test (Gowthamrajan et al., 2002) the formulation was filled to about $1 \mathrm{~cm}$ height in capillary tubes of $10 \mathrm{~cm}$ length and dipped in a beaker containing water. The temperature was raised slowly and the temperature at which the mass liquefies was recorded.

\section{In vitro dissolution studies}

In vitro dissolution studies of ACL suppositories were carried out in USP XIII tablet dissolution test apparatus (Electrolab-TDT 06N), employing a rotating basket at $50 \mathrm{rpm}$ and using $900 \mathrm{ml}$ of $\mathrm{pH} 7.4$ phosphate buffer at $37 \pm 0.5^{\circ} \mathrm{C}$ as dissolution medium. One suppository was used in each test. At predetermined time intervals, $5 \mathrm{ml}$ samples were withdrawn by means of a syringe fitted with a pre- 


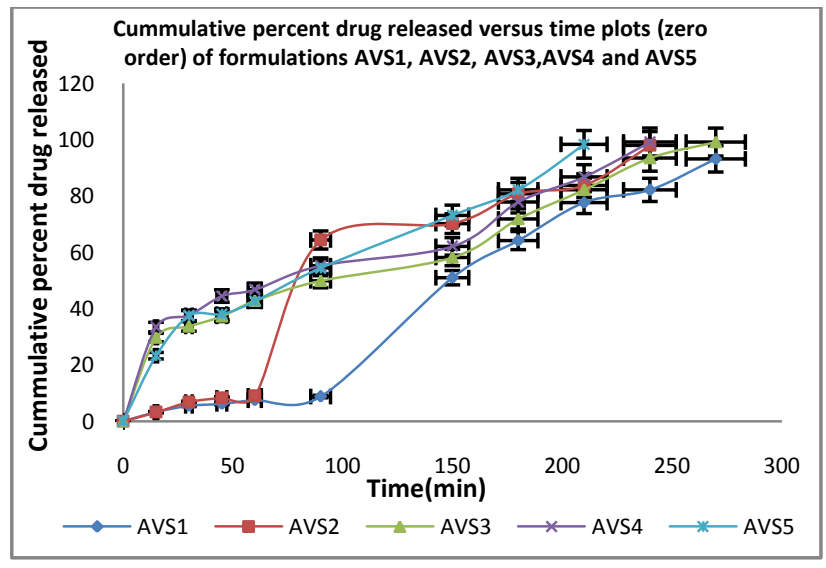

Figure 1: Cumulative percent drug release vs. time plots of hydrogenated vegetable oil-beeswax suppositories.

filter. The volume withdrawn at each interval was replaced with same quantity of fresh dissolution medium maintained at $37 \pm 0.5^{\circ} \mathrm{C}$. The samples were analyzed for drug release by measuring the absorbance at 276nm using UV-visible spectrophotometer after suitable dilution. Cumulative percent of ACL released was calculated and plotted against time (figure 1-2). All the studies were run in triplicate $(n=3)$.

\section{Stability studies}

Short-term stability studies were performed at a temperature of $25 \pm 3^{\circ} \mathrm{C} / 60 \pm 5 \% \mathrm{RH}$ over a period of 6 months on the promising suppository formulation $\left(\mathrm{AVS}_{3}\right)$. Sufficient number of suppositories (20) were individually wrapped in aluminium foil and packed in card-board boxes. Samples are taken at 0, 3 and 6 month intervals for drug content estimation. At the end of 6 month period, dissolution test was also performed to determine the drug release profile.

\section{Drug-excipient interaction study}

FTIR study was done to evaluate interactions between the drug and polymer. The IR spectra of aceclofenac had shown characteristic peaks at 750.17 $\mathrm{cm}^{-1}, 668.21 \mathrm{~cm}^{-1}$ (C-Cl stretch), $717.39 \mathrm{~cm}^{-1}$ (C=O stretch), $1256.4 \mathrm{~cm}^{-1}, 1151.29 \mathrm{~cm}^{-1}$ (C-0 stretch), $1056.2 \mathrm{~cm}^{-1}$ (C-N stretch) and $1453.1 \mathrm{~cm}^{-1}(\mathrm{C}-\mathrm{C}$ stretch in ring) $1717.4 \mathrm{~cm}^{-1}\left(\mathrm{C}=\mathrm{O}\right.$ stretch), $1771 \mathrm{~cm}^{-1}$ (ester $\mathrm{C}=\mathrm{O}$ stretch) respectively. Whereas, the prominent peak of secondary amine was appeared at $3318 \mathrm{~cm}^{-1}$, The IR spectra of aceclofenac and suppository had exhibited similar characteristic

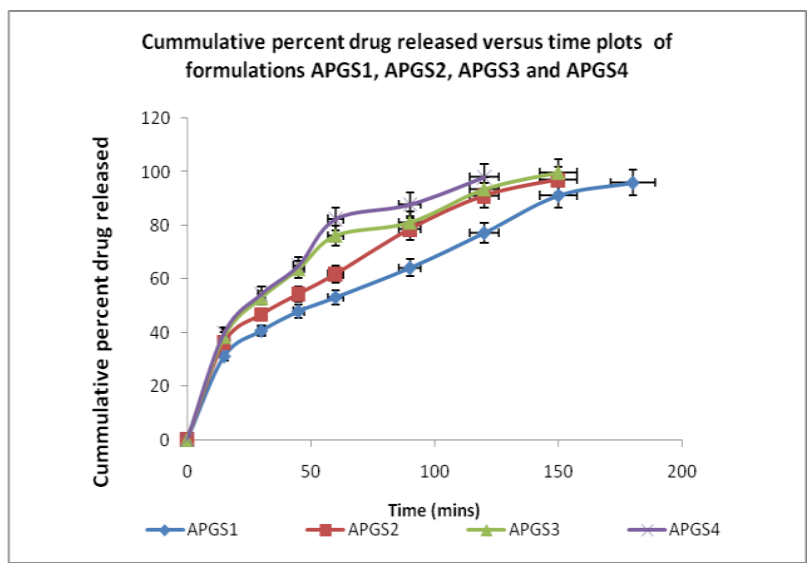

Figure 2: Cumulative percent drug release vs time plots of gelatin-propylene glycol-PEG 400 suppositories.

peaks of pure drug which confirmed that there was no interaction between the drug and the polymer.

The DSC thermogram of aceclofenac exhibit sharp endothermic peak at $153.97^{\circ} \mathrm{C}$ corresponds to its melting point figure 3. Similarly hydrogenated vegetable oil exhibited one endothermic peak with an onset temperature $13.30^{\circ} \mathrm{C}$ and peak at $30.99^{\circ} \mathrm{C}$ with slight decomposition peak corresponds to the melting point of vegetable oil figure 4 .

The DSC thermogram of mixture exhibited onset at $13.8^{\circ} \mathrm{C}$ and peak at $26.92^{\circ} \mathrm{C}$ indicating slight shift of endothermic peak of hydrogenated vegetable oil (figure 5) The characteristic endothermic drug peak has completely disappeared and appearance of additional endothermic peak at $43.05^{\circ} \mathrm{C}$ indicates drug is completely dissolved in the hydrogenated vegetable oil suggesting that drug has changed into amorphous form The DSC results reveal that there is a possible interaction at molecular level without affecting the potency of the drug.

\section{RESULTS AND DISCUSSION}

Suppositories of ACL, an NSAID drug, were prepared by fusion method using hydrogenated vegetable oil (AVS 1 to $A V S_{5}$ ), and gelatin-PEG 400 (APGS 1 to $\mathrm{APGS}_{4}$ ) as bases, beeswax for increasing the melting point of hydrogenated vegetable oil and propylene glycol as plasticizer. The prepared suppositories were evaluated for appearance, weight variation, drug content uniformity, liquefaction time and temperature, micro-melting range, in 


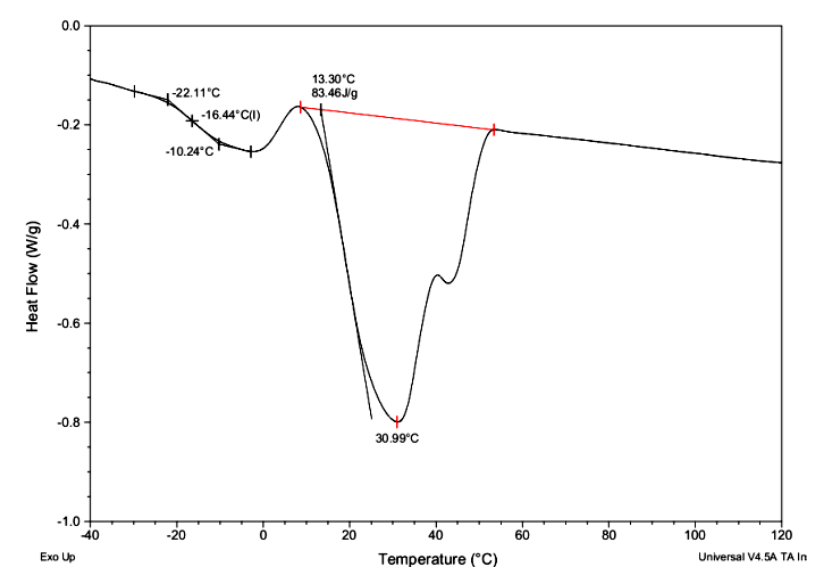

Figure 3: DSC thermogram of hydrogenated Vegetable oil.

vitro dissolution, short-term stability. The moulds (1g capacity) were calibrated for different bases used. The calibrated mould capacities ranged from 1.02 to $1.32 \mathrm{~g}$. All the suppositories were free from pits, fissures and cracks. The longitudinal section of the suppositories was opaque and uniform in appearance, indicating complete and even distribution of drug in the base.

The prepared suppositories were evaluated for uniformity of weight and the results are given in Table 2. The percent deviation from the mean weights of all batches was found to be within the prescribed limits (average weight \pm 5 to $7.5 \%$ ) as per Indian Pharmacopoeia. The drug content was found to be in the range of $95.58 \%$ to $98.77 \%$, which is within the acceptable limits. The low values of standard deviation indicated uniform drug content within the suppositories prepared. Melting/ softening time is the time at which the suppositories withstand body temperature of $37^{\circ} \mathrm{C}$, which is helpful in convenient handling and release of the drug after administration in the rectum.

The suppositories prepared with hydrogenated vegetable oils alone were not hard and were melting at a temperature below $37^{\circ} \mathrm{C}$; the addition of beeswax in the formulation increased the melting temperature and hardness. In case of hydrogenated vegetable oil-beeswax suppositories, the liquefaction time and temperature were found to be in the range of 3 to $6 \mathrm{~min}$ at $37 \pm 1^{\circ} \mathrm{C}$, while with gelatinPEG 400 suppositories, the liquefaction time was found to be in the range of 3 to $4 \mathrm{~min}$ at $37 \pm 1^{\circ} \mathrm{C}$. The temperature for micro-melting of hydrogenated vegetable oil suppositories was between 36 to $39^{\circ} \mathrm{C}$

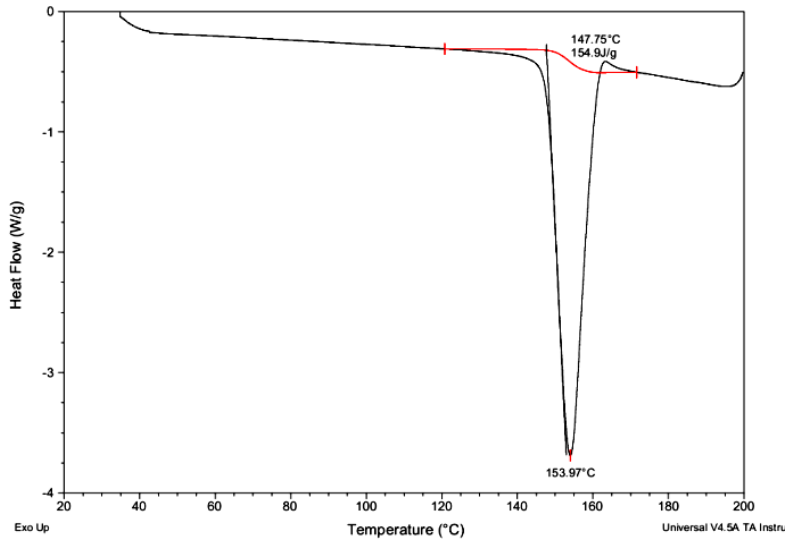

Figure 4: DSC thermogram of Aceclofenac.

and for gelatin-PEG 400 suppositories it was found to be in between 36 to $38^{\circ} \mathrm{C}$ in all the batches.

In vitro dissolution studies on the formulated hydrogenated vegetable oil- beeswax suppositories $\left(\mathrm{AVS}_{1}\right.$ to $\left.\mathrm{AVS}_{5}\right)$ and the gelatin-PEG 400 based suppositories (APGS 1 to $\mathrm{APGS}_{4}$ ) were carried out in $\mathrm{pH} 7.4$ phosphate buffer and the various dissolution parameter values, viz., percent drug dissolved , $\mathrm{t}_{50} \%$ and $t_{70 \%}$ are shown in Table 3 and the dissolution profiles depicted in Figure 1 and 2. This data shows that hydrogenated vegetable oil-beeswax suppositories have released upto $99.18 \%\left(\mathrm{AVS}_{3}\right.$, which contains $7.5 \% \mathrm{w} / \mathrm{w}$ bees wax) of the drug in $4 \mathrm{~h}$, while gelatin-PEG 400 suppositories upto $99.75 \%$ (APGS 3 , which contains 15\% w/w of PEG-400) of the drug in $2.5 \mathrm{~h}$. In case of the formulations $\mathrm{AVS}_{1}$ to $\mathrm{AVS}_{5}$, which consist of hydrogenated vegetable oilbeeswax suppository base, the release rate decreases as the concentration of the beeswax increases; this might be due to the increase in melting time.

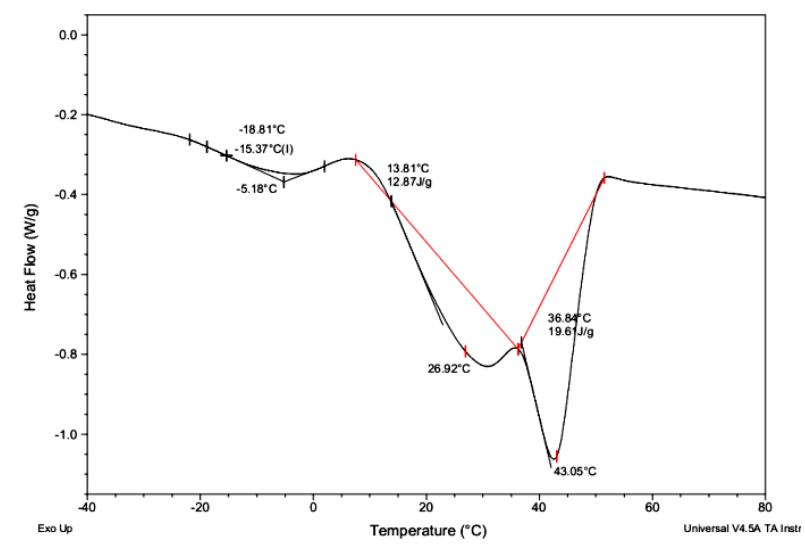

Figure 5: DSC thermogram of $\mathrm{AVS}_{4}$. 


\section{Drug release kinetics}

The in vitro drug release data was subjected to goodness of fit test by linear regression analysis, according to first-order kinetic equations, Higuchi and Peppas models, to determine the mechanism of drug release. The regression coefficient ' $r$ ' values for Higuchi's equation range from 0.9547 to 0.9967 indicating that the drug release is by diffusion mechanism, and those of ' $n$ ' values of Peppas equation range from 0.4128 to 1.465 . As per the ' $n$ ' values of Peppas equation, the prepared suppositories have shown Fickian $\left(\mathrm{AVS}_{4}, \mathrm{APGS}_{3}\right.$ and $\mathrm{APGS}_{4}$, $\mathrm{n}<0.45$ ), non-Fickian $\left(\mathrm{AVS}_{3}, \mathrm{AVS}{ }_{5}, \mathrm{APGS}_{1}, \mathrm{APGS}_{2}\right.$, $0.89>\mathrm{n}>0.45)$ and super case-II $\left(\mathrm{AVS}_{1}\right.$ and $\mathrm{AVS}_{2}$, $\mathrm{n}>1.0$ ) release mechanism. The super case-II release mechanism may be attributed to burst- effect displayed by these formulations, this, in turn, might be because of high concentration of beeswax ( 8.75 to $10 \% \mathrm{w} / \mathrm{w})$. The formulation $\mathrm{AVS}_{3}$ containing $7.5 \% \mathrm{w} / \mathrm{w}$ beeswax in hydrogenated vegetable oil has displayed zero-order release rate $(r=0.9927)$, hence this formulation can be considered as promising formulation and it has released $99.18 \%$ ACL within $4 \mathrm{~h}$. All the formulations except $\mathrm{GS}_{3}$ and $\mathrm{GS}_{4}$ have shown zero-order drug release kinetics.

\section{Stability studies}

Short-term stability studies of the above formulation indicated that there are no significant changes in drug content and in vitro dissolution parameters ( $\mathrm{t}_{50 \%}$ and $\mathrm{t} 70 \%$ values during a period of 6 months.

\section{REFERENCES}

Basvaraj, B.V, Nanjundaswamy, N.G. (2005). Formulation and evaluation of paracetamol suppositories adapting various bases and adjuvants, Indian Drugs, Volume 42, Issue 5, Pages 305-308.

Carter S.J. (2008). Cooper and Gun's Dispensing for Pharmaceutical Students, CBS Publishers, New Delhi, $12^{\text {th }}$ ed., pp. 232-252.

Coben, L.J., Liberman, H.A. (1989) Theory and Practice of Industrial Pharmacy, Mumbai, Varghese Publishing House, $3^{\text {rd }}$ ed., p.580.

Gowthamarajan, K., Kulkarni, T.G., Venkateswaran, G., Samanta, M.K., Suresh, B. (2002). Formulation and dissolution of meloxicam solid dispersion incorporated suppositories, Indian Journal of Pharmaceutical Sciences, Volume 64, Issue 6, Pages 525-528.

Hermann, T.W. (1995). Recent research on bioavailability of drugs from suppositories, Int. J. Pharm., Volume 123, 1-11. [DOI]

Indian Pharmacopoeia, Vol 2, Govt of India, Controller of Publications, New Delhi, 1996. p. 572.

Rawlins, E.A.(2002). Bentley's Text Book of Pharmaceutics Delhi, All India Traveller Book Seller, $8^{\text {th }}$ ed., pp. 347-50.

Rytting, J.H., Fix, J.A. (2002). Encyclopedia of Pharmaceutical Technology, New York, Marcel Dekker Inc., $2^{\text {nd }}$ ed., Pp. 932-943.

Sweetman S.C. (2005). Martindale: The Complete Drug Reference London, Pharmaceutical Press, $34^{\text {th }}$ ed., p. 865 .

The British Pharmaceutical Codex (1968), Pharmaceutical Press London, p.1262.

\section{CONCLUSION}

It can be concluded that rectal suppositories of aceclofenac can be prepared by utilizing both hydrophobic and hydrophilic bases, and hydrogenated vegetable oil along with beeswax can be considered as a potential suppository base with zero-order drug release for the drug aceclofenac. Invivo studies are required to ascertain the results obtained with in-vitro drug release studies. 